\title{
Infarto esplénico masivo en un paciente pediátrico sin factores predisponentes
}

\author{
Massive splenic infarct in a pediatric patient without predisposing factors
}

\author{
Dra. Bárbara Rivera Fernández Galán ${ }^{a}$ Dr. Oscar González Llano ${ }^{b}$, Dr. César A. Martínez Longoriac $y$ \\ Dra. María M. Rangel Fuentes ${ }^{d}$
}

\section{RESUMEN}

Elinfarto esplénico es una entidad rara en la edad pediátrica que, cuando se encuentra, se asocia a otros factores predisponentes, como enfermedades oncológicas, hematológicas o infecciosas. Su presentación es asintomática o sintomática con dolor abdominal, fiebre y esplenomegalia. No existe consenso sobre cuál es la mejor opción de tratamiento, y se decide, en la mayoría de los casos, un manejo conservador o quirúrgico de acuerdo con las características individuales del paciente. Se presenta el caso de un paciente escolar que acude por un cuadro de dolor abdominal agudo y fiebre con diagnóstico de infarto esplénico masivo sin etiología aparente que fue manejado de manera conservadora, con evolución favorable. Es importante considerar este padecimiento como causa de dolor abdominal asociado a esplenomegalia y destacar la relevancia de esta presentación de caso, ya que se presenta sin relación con enfermedades subyacentes.

Palabras clave: infarto esplénico, esplenomegalia, idiopática, pediatría.

\section{ABSTRACT}

Splenicinfarction is a rare entity in the paediatric age that, when found, is associated with other predisposing factors such as oncological, haematological or infectious diseases. It is whether asymptomatic or symptomatic with abdominal pain, fever and splenomegaly. There is no consensus on which is the best treatment option, in most cases deciding conservative or surgical management according to individual patient characteristics. We present the case of a patient with acute abdominal pain and fever with a diagnosis of massive splenic infarction without apparent aetiology that was managed conservatively with favourable evolution. It is important to consider this condition as a cause of abdominal pain associated with splenomegaly. Key words: splenic infarct, splenomegaly, idiopathic, pediatrics.
\end{abstract}

a. Escuela de Medicina, Tecnológico de Monterrey, Monterrey, Nuevo León, México.

b. Servicio de Hematología Pediátrica, Hospital

Universitario, Universidad Autónoma de Nuevo León, México.

c. Hospital San José, Tecnológico de Monterrey, Monterrey, Nuevo León, México.

d. Hospital Regional Materno Infantil, Guadalupe, Nuevo León, México.

\section{Correspondencia:}

Dra. Bárbara Rivera Fernández Galán: barbara.rifg@gmail.com

Financiamiento: Ninguno.

Conflicto de intereses: Ninguno que declarar.

Recibido: 5-5-2018

Aceptado: 14-1-2019 http:/ / dx.doi.org/10.5546/aap.2019.e387

Cómo citar: Rivera Fernández Galán B, González Llano O, Martínez Longoria CA, Rangel Fuentes MM. Infarto esplénico masivo en un paciente pediátrico sin factores predisponentes. Arch Argent Pediatr 2019;117(4):e387-e392.

\section{INTRODUCCIÓN}

El infarto esplénico masivo es una entidad poco frecuente. Se realiza el diagnóstico en más del $90 \%$ de los casos en estudios post mortem. ${ }^{1}$ Sin embargo, encontrar a un paciente con dolor abdominal y fiebre es una situación común con una amplia gama de diagnósticos diferenciales, entre los que se incluye la esplenomegalia, que podría considerarse un signo aislado y común en muchos padecimientos que se presentan con dolor y / o distensión abdominal y que puede explicarse por procesos infiltrativos, hemólisis crónica $^{2}$ y, de manera inusual, por los infartos esplénicos masivos.

La esplenomegalia explicada por un infarto esplénico masivo es muy poco común. Ocurre, por lo general, cuando se tiene alguna enfermedad de base, principalmente, hematológica, oncológica o infecciosa, por lo que no se considera una opción diagnóstica de primera instancia en pacientes sanos y pasa inadvertida hasta en un $25 \%$ de los casos. ${ }^{3}$ Dentro de la literatura, se encuentra muy poca evidencia respecto a este padecimiento, por lo que se dificulta aún más su diagnóstico. ${ }^{4}$ Tiene una evolución aguda y se llega a confundir con un abdomen agudo quirúrgico, con la diferencia de que, tras hacerse el diagnóstico, el tratamiento puede ser conservador y se realizan estudios de imagen seriados de control.

Se busca describir el caso y la evolución clínica de un niño que presenta esplenomegalia asociada a un infarto esplénico masivo, en el que no se encontró una enfermedad de base para explicar su aparición y se analizaron las controversias en cuanto a su diagnóstico y manejo. 


\section{REPORTE DE CASO}

Escolar de 8 años de edad que acudió al Hospital Regional Materno Infantil, en Nuevo León, México, por un cuadro de dos días de evolución de náusea y dolor abdominal súbito, tipo cólico, no localizado, referido por la madre como autopalpación constante en la región abdominal. Se sospechó un cuadro de constipación y se indicó, inicialmente, el tratamiento con laxante; sin embargo, se agregaron evacuaciones disminuidas en consistencia y fiebre.

Como antecedentes, contaba con el diagnóstico de trastorno del espectro autista desde los 30 meses de edad, en tratamiento con risperidona, y constipación desde los 4 años, manejada con lactulosa de manera intermitente.

Debido a la persistencia de los síntomas, se decidió su ingreso al Servicio de Pediatría
General, y se encontró, en ese momento, febril, taquicárdico y con abdomen timpánico con áreas de matidez no delimitadas, rigidez involuntaria con hiperalgesia y movimiento de retirada ante la palpación del cuadrante superior izquierdo, sin poder identificar visceromegalias ni realizar la exploración abdominal completa por la poca cooperación del paciente.

Los estudios de laboratorio demostraron leve anemia normocítica normocrómica, con leucocitosis a expensas de neutrofilia (Tabla 1), y el ultrasonido abdominal reportó el bazo de $17 \mathrm{~cm}$ en su eje longitudinal con un área redondeada en el polo inferior de $9 \mathrm{~cm}$ de diámetro, por lo que se estableció el diagnóstico de absceso esplénico. Se tomó el hemocultivo y se inició el esquema de antibiótico con clindamicina $(30 \mathrm{mg} / \mathrm{kg} /$ día) y cefotaxima (100 mg/ kg/ día). La fiebre cedió al segundo día de hospitalización y disminuyó,

TABLA 1. Estudios iniciales de laboratorio

\begin{tabular}{|c|c|c|}
\hline \multicolumn{3}{|l|}{ Biometría hemática completa } \\
\hline Hemoglobina & $9,87 \mathrm{~g} / \mathrm{dl}$ & $11,5-13,5$ \\
\hline Hematocrito & $29,64 \%$ & $35-43$ \\
\hline VCM & $85,40 \mathrm{fL}$ & $77-90$ \\
\hline $\mathrm{HCM}$ & $28,45 \mathrm{pg}$ & $27-32$ \\
\hline $\mathrm{CMHC}$ & $33,31 \mathrm{~g} / \mathrm{dl}$ & $31-34$ \\
\hline RDW & $12,76 \%$ & \\
\hline Leucocitos & $21,74 \times 10^{3} / \mathrm{ul}$ & $4,5-13,5$ \\
\hline Neutrófilos & $17,15 \times 10^{3} / \mathrm{ul}$ & $1,5-8$ \\
\hline Linfocitos & $2,56 \times 10^{3} / \mathrm{ul}$ & $1,5-6,8$ \\
\hline Monocitos & $1,80 \times 10^{3} / \mathrm{ul}$ & $0,4-0,6$ \\
\hline Eosinófilos & $0,05 \times 10^{3} / \mathrm{ul}$ & $0,2-0,5$ \\
\hline Basófilos & $0,17 \times 10^{3} / \mathrm{ul}$ & \\
\hline Plaquetas & $243,4 \times 10^{3} / \mathrm{ul}$ & $150-350$ \\
\hline \multicolumn{3}{|l|}{ Perfil bioquímico } \\
\hline Examen & Resultado & Valores de referencia \\
\hline Bilirrubina total & $0,40 \mathrm{mg} / \mathrm{dl}$ & $<1,5$ \\
\hline Bilirrubina directa & $0,20 \mathrm{mg} / \mathrm{dl}$ & $<0,2$ \\
\hline Bilirrubina indirecta & $0,20 \mathrm{mg} / \mathrm{dl}$ & \\
\hline Proteínas totales & $7,7 \mathrm{~g} / \mathrm{dl}$ & $6-8$ \\
\hline Albúmina & $3,8 \mathrm{~g} / \mathrm{dl}$ & $3,6-5,2$ \\
\hline Globulina & $3,9 \mathrm{~g} / \mathrm{dl}$ & \\
\hline Relación A/G & 0,97 & \\
\hline TGO (ALT) & $6 \mathrm{U} / 1$ & $10-35$ \\
\hline TGP (AST) & $17 \mathrm{U} / 1$ & $15-40$ \\
\hline Fosfatasa alcalina & $112 \mathrm{U} / 1$ & $100-320$ \\
\hline Gamma-glutamil transferasa & $15 \mathrm{U} / 1$ & $5-32$ \\
\hline DHL & $442 \mathrm{U} / 1$ & $110-295$ \\
\hline
\end{tabular}

g/dl: gramos por decilitro; fL: fentolitros; pg: picogramos; mg/dl: miligramos por decilitro; U/l: unidades por litro;

VCM: volumen corpuscular medio; HCM: hemoglobina corpuscular media; CMHC: concentración media de hemoglobina corpuscular; RDW: amplitud de la distribución eritrocitaria; relación A/G: relación de albúmina a globulinas;

TGO (ALT): transaminasa glutámico-oxalacética (aspartato-aminotransferasa; TGP (AST): transaminasa glutámico-pirúvica (alanino-aminotransferasa); DHL: deshidrogenasa láctica. 
progresivamente, el dolor abdominal, por lo que, al $8^{\text {vo }}$ día del ingreso, se realizó una tomografía axial computarizada de abdomen con contraste intravenoso (Figuras 1 y 2 ) y se encontraron datos sugestivos de infarto esplénico masivo. Se solicitó la evaluación por el Servicio de Hematología al $9^{\text {no }}$ día de hospitalización, quienes indicaron el tratamiento con enoxaparina ( $2 \mathrm{mg} / \mathrm{kg} /$ día) durante 5 días y se solicitaron estudios de laboratorio como complementación diagnóstica (Tabla 2) para buscar descartar las causas más frecuentes asociadas a infartos esplénicos, como la infección por citomegalovirus y virus de Epstein-
Barr, además de deficiencias de las proteínas C y S. Todos estos exámenes se presentaron como negativos. Se mantuvo bajo vigilancia, con mejoría de la sintomatología y disminución de las dimensiones del bazo, y se decidió su egreso al $16^{\mathrm{vo}}$ día, sin tratamiento médico y con la indicación de cobertura vacunal contra bacterias encapsuladas (Streptococcus pneumoniae, Neisseria meningitidis y Haemophilus influenzae tipo b). El paciente no acudió a la cita de seguimiento el mes posterior al egreso ni a realizarse un ultrasonido abdominal, y no pudieron ser contactados sus familiares por la trabajadora social.

FIGURA 1. El bazo se encuentra desplazado caudalmente y aumentado de tamaño; mide alrededor de 14,7 x 6,3 centímetros, y no se evidencian lesiones focales

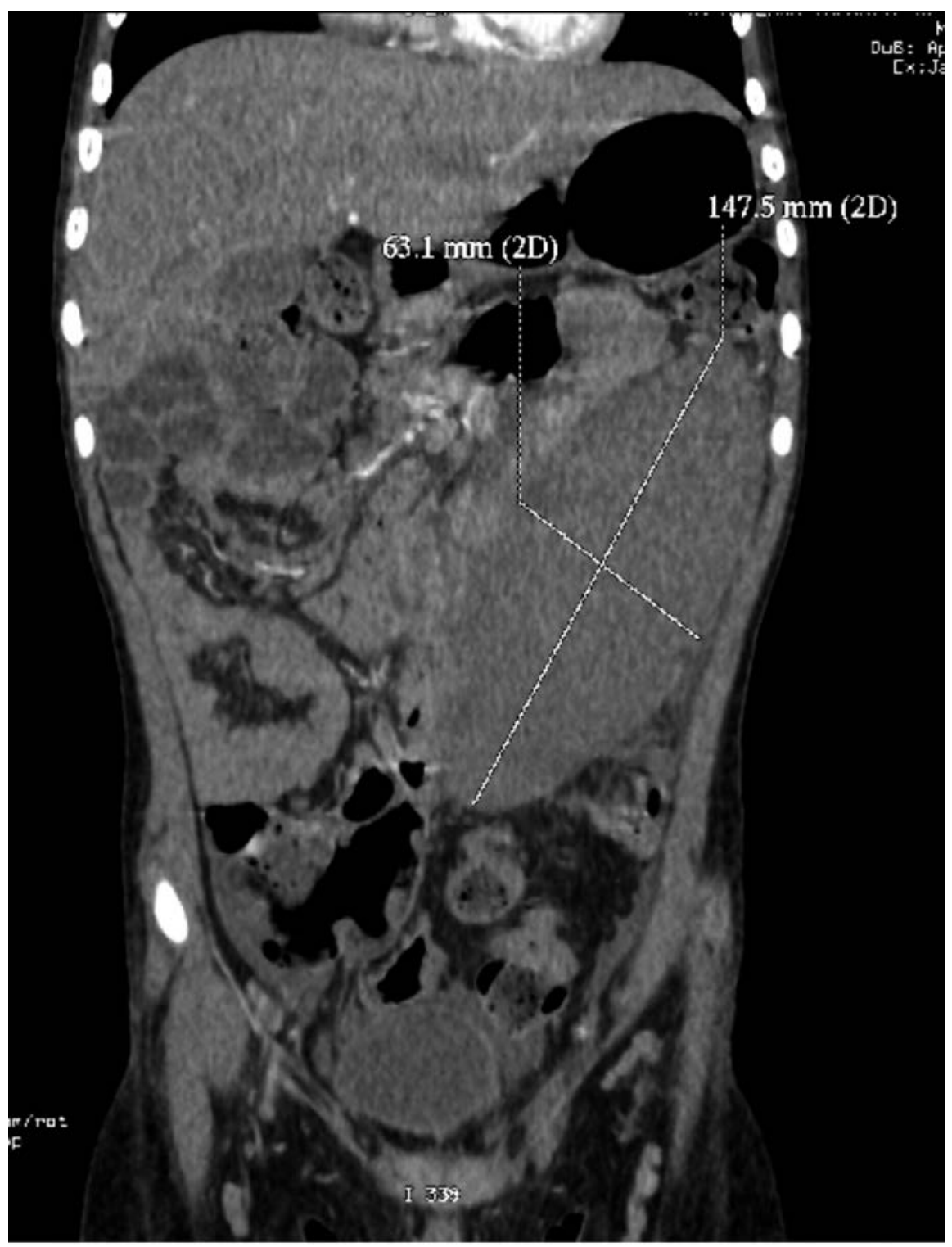


FIGURA 2. Durante las fases arterial y venosa, no se observa el reforzamiento habitual del bazo; se muestra de aspecto hipodenso en forma difusa y homogénea, y solo se ve la parte inicial de la arteria esplénica y de la vena esplénica sin lograr evidenciar su llegada al hilio esplénico

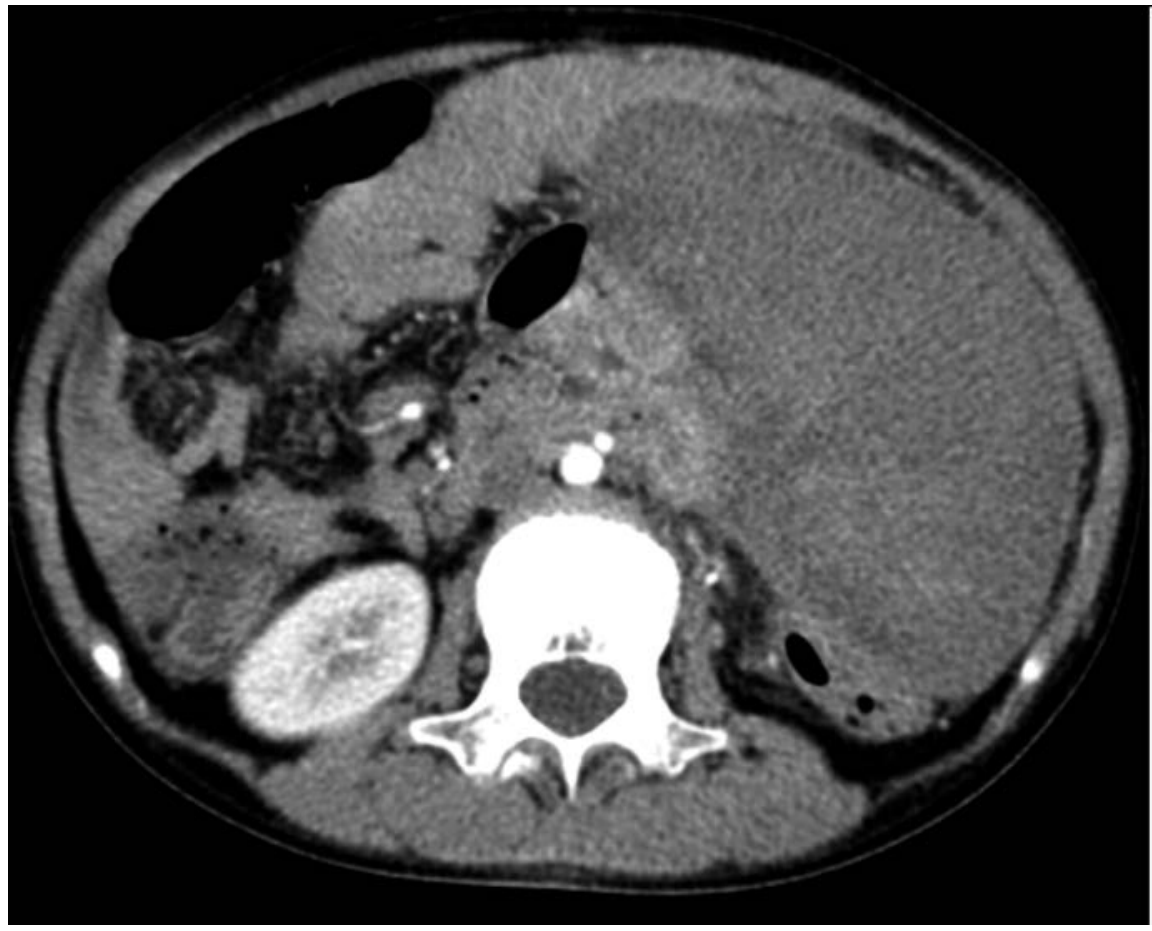

TABLA 2. Estudios realizados para enfermedades infecciosas, autoinmunes, trombofilias y enfermedades hematológicas en el caso

\begin{tabular}{|c|c|c|}
\hline Examen & Resultados & Valores de referencia \\
\hline ELISA para el virus de la inmunodeficiencia humana (VIH) & Negativo & Negativo \\
\hline Prueba no treponémica (VDRL) & Negativo & Negativo \\
\hline \multicolumn{3}{|l|}{ Perfil de virus de Epstein-Barr } \\
\hline Anticuerpo frente al antígeno temprano & 0,4 & $<0,8$ \\
\hline Anticuerpo frente a IgG cápside & 7,9 & $<0,9$ \\
\hline Anticuerpo frente a IgM cápside & 0,92 & $<0,9$ \\
\hline Anticuerpo frente a IgG antígeno nuclear & 2,74 & $<0,8$ \\
\hline \multicolumn{3}{|l|}{ Perfil de citomegalovirus } \\
\hline Anticuerpos IgG & $500 \mathrm{UA} / \mathrm{ml}$ & $<0,85$ \\
\hline Anticuerpos IgM & $0,20 \mathrm{pg} / \mathrm{ml}$ & $<6$ \\
\hline \multicolumn{3}{|l|}{ Frotis de sangre periférica } \\
\hline Morfología de la serie roja & Hipocromía ++ & \\
\hline \multicolumn{3}{|l|}{ Eritrocitos normocíticos } \\
\hline Morfología de la serie blanca & Eosinofilia & \\
\hline \multicolumn{3}{|l|}{ Leucocitos con morfología y madurez normales } \\
\hline Morfología de las plaquetas & Se observan macroplaquetas. & \\
\hline \multicolumn{3}{|l|}{ Trombocitosis (1600000: cuenta manual) } \\
\hline Anticoagulante lúpico en plasma & No detectado & \\
\hline \multicolumn{3}{|l|}{ Anticuerpos anticardiolipinas } \\
\hline $\operatorname{IgG}$ & 1 & $<0,86$ \\
\hline $\operatorname{IgM}$ & 0,4 & $<0,87$ \\
\hline Proteína C (actividad) en plasma & $137 \%$ & $70-140 \%$ \\
\hline Proteína S (actividad) en plasma & $104 \%$ & $58-127,5 \%$ \\
\hline
\end{tabular}

$\mathrm{UA} / \mathrm{ml}$ : unidades de absorbancia por mililitros; pg/ml: picogramo por mililitro; ELISA: ensayo por inmunoabsorción ligado a enzimas; VDRL: prueba serológica para la sífilis; IgG: inmunoglobulina G; IgM: inmunoglobulina M. 


\section{DISCUSIÓN}

El infarto esplénico masivo es una entidad poco frecuente, más aún en niños, pues se diagnostica, en un $90 \%$ de los casos, en estudios post mortem. ${ }^{1}$ Se encuentran solamente publicadas seis series de casos, que incluyen pacientes de todos los grupos etarios. Esta patología se explica por un compromiso en la irrigación arterial del bazo, la cual es segmentaria y terminal, y se pueden encontrar infartos parciales o masivos de acuerdo con las arterias involucradas. ${ }^{5}$ En la gran mayoría de los casos, se encuentra asociado a un grupo heterogéneo de enfermedades, que incluyen las mieloproliferativas, linfomas, hemoglobinopatías, estados protrombóticos, infecciones o traumatismos, $\mathrm{y}$, solamente en alrededor de un tercio de los pacientes, no se logra evidenciar alguna patología predisponente, como es el caso del nuestro.

Su presentación, de acuerdo con William Osler, oscila desde asintomática en un tercio de los pacientes o hasta en un $50 \%$ de ellos a manifestarse como dolor abdominal agudo en el hipocondrio izquierdo con irradiación al hombro del mismo lado relacionado o no con esplenomegalia, o a presentarse como síndrome febril, lo que la hace indistinguible de otras patologías abdominales. ${ }^{1,2}$

Nuestro paciente no contaba con ninguna enfermedad de base predisponente para el infarto esplénico, lo que no lo hacía un diagnóstico presuntivo inicial. Más aún, su presentación de dolor abdominal y síndrome febril, si bien, de acuerdo con la literatura, era característica de un infarto esplénico, también lo era de muchas otras patologías.

Los estudios de laboratorio son inespecíficos $\mathrm{y}$ se puede encontrar leucocitosis, trombocitosis o anemia, además de una elevación de la deshidrogenasa láctica durante las etapas tempranas. ${ }^{3}$ En este caso, presentaba leucocitosis y una leve elevación de deshidrogenasa láctica como únicos estudios de laboratorio alterados. Son necesarios estudios de imagen para realizar un diagnóstico certero. ${ }^{6}$ aunque, en estos, es frecuente el reporte de una imagen sugestiva de un absceso bacteriano, como en este caso. En estudios retrospectivos, el ultrasonido tiene una sensibilidad de solo un $18 \%$ y se reportan estas zonas de infarto como abscesos. ${ }^{7,8}$ El estándar de oro para realizar el diagnóstico es la tomografía axial computarizada, donde se pueden observar áreas cuneiformes hipointensas que corresponden al área infartada. En este caso, se observó una homogeneidad hipointensa del bazo que sugirió un infarto masivo.

Las etiologías más frecuentes relacionadas con esplenomegalia masiva son leucemia mieloide crónica, mielofibrosis primaria, mielofibrosis secundaria a policitemia vera o trombocitosis primaria, enfermedad de Gaucher, linfoma de células pequeñas, leucemia de células peludas, kala azar (leishmaniasis visceral), talasemia mayor y el síndrome palúdico con esplenomegalia reactiva, conocida como esplenomegalia tropical. ${ }^{5,9}$ Prácticamente, todas ocurren en la edad adulta, y muy pocas de ellas en la edad pediátrica. Casi todas se pueden descartar debido a la edad de presentación, a la evolución y a los estudios de laboratorio iniciales, así como los estudios complementarios de diagnóstico.

Las complicaciones que se pueden presentar secundarias a un infarto esplénico masivo incluyen la formación de abscesos, hemorragia o ruptura. Esta última no es tan común, ya que la cápsula del bazo se encuentra íntegra. ${ }^{1}$ La esplenectomía debe ser considerada para el manejo agudo de cualquiera de estas complicaciones o debe programarse de forma electiva en casos de dolor abdominal constante o hiperesplenismo. No existe un consenso sobre el mejor tratamiento para estos pacientes, ${ }^{8}$ pero lo que sí es claro es que se comportan como pacientes esplenectomizados, ya que el bazo pierde su capacidad funcional, lo que genera un mayor riesgo de presentar trombocitosis y una mayor predisposición para desarrollar episodios de sepsis por bacterias encapsuladas, como Streptococcus pneumoniae, Haemophilus influenzae tipo b y Neisseria meningitidis, ${ }^{5}$ por lo que la vacunación es vital. Así mismo, el seguimiento del conteo plaquetario, además de la evaluación del tamaño del bazo por medio de ultrasonido, son piedra angular del manejo conservador. ${ }^{8}$

No se pudo tener registro de la evolución del paciente, debido a que no acudió a su consulta de seguimiento; sin embargo, fue posible la administración de las vacunas recomendadas antes de su egreso.

Aunque el infarto esplénico masivo, usualmente, se presenta como un evento secundario a diversas patologías, también puede ocurrir como un evento primario. Se sospecha en casos de enfermedades que predispongan a hemólisis o trombosis que desarrollen dolor abdominal en el hipocondrio izquierdo o en los casos de esplenomegalia con fiebre sin foco aparente, y se establece el diagnóstico definitivo 
con una tomografía de abdomen. ${ }^{1,10}$ Se insiste en que, en un 15-30 \% de los casos, como en nuestro paciente, no es posible establecer un diagnóstico etiológico definitivo ${ }^{1}$ y se destaca que, sin importar la causa, el manejo que se le dará al paciente, ya sea conservador o quirúrgico, involucra un seguimiento estrecho y una protección vacunal rigurosa.

\section{REFERENCIAS}

1. Antopolsky M, Hiller N, Salameh S, Goldshtein B, et al. Splenic infarction: 10 years of experience. Am J Emerg Med. 2009; 27(3):262-5.

2. Friedman-Klabanoff D, Ball A, Rutare $\mathrm{S}, \mathrm{McC}$ all N, et al. Three Rwandan Children With Massive Splenomegaly and Epstein-Barr Virus-associated Lymphoproliferative Disorders: Case Presentations and the Literature Review. J Pediatr Hematol Oncol. 2016; 38(5):e158-61.

3. Kranidiotis G, Efstratiadis E, Kapsalakis G, Loizos G, et al. Splenic infarcts as a rare manifestation of parvovirus B19 infection. IDCases. 2016; 4:62-4.
4. Naviglio S, Abate MV, Chinello M, Ventura A. Splenic Infarction in Acute Infectious Mononucleosis. J Emerg Med. 2016; 50(1):e11-3.

5. Vargas Viveros P, Hurtado Monroy R, Villalobos Alba JA. Esplenomegalia. Rev Fac Med (Méx en línea). 2013; 56(2):37-45.

6. Lawrence YR, Pokroy R, Berlowitz D, Aharoni D, et al. Splenic infarction: an update on William Osler's observations. Isr Med Assoc J. 2010; 12(6):362-5.

7. Ricci ZJ, Oh SK, Chernyak V, Flusberg M, et al. Improving diagnosis of atraumatic spleniclesions, part I: nonneoplastic lesions. Clin Imaging. 2016; 40(4):769-79.

8. D'Angelo G, Marseglia L, Russo T, Gitto E, et al. Longterm follow up of a massive, conservatively treated, splenic infarction in a young adolescent. Pediatr Int. 2017; 59(11):1210-2.

9. Heo DH, Baek DY, Oh SM, Hwang JH, et al. Splenic infarction associated with acute infectious mononucleosis due to Epstein-Barr virus infection. J Med Virol. 2017; 89(2):332-6.

10. Bhattarai P, Pierr L, Adeyinka A, Sadanandan S. Splenic Infarct: A Rare Presentation in a Pediatric Patient. JNMA J Nepal Med Assoc. 2014; 52(196):1017-9 